LA-UR- $98-2385$

\title{
Simulation of the SRI International Test Gun-27 Using the PAGOSA Code
}

\author{
Jerome J. Jacoby
}

\section{Nuclear and Hydrodynamics Applications Group}

\section{Applied Theoretical and Computational Physics Division Los Alamos National Laboratory}

June 23, 1997

\section{DISCLAIMER}

This report was prepared as an account of work sponsored by an agency of the United States Government. Neither the United States Government nor any agency thereof, nor any of their employees, makes any warranty, express or implied, or assumes any legal liability or responsibility for the accuracy, completeness, or usefulness of any information, apparatus, product, or process disclosed, or represents that its use would not infringe privately owned rights. Reference herein to any specific commercial product, process, or service by trade name, trademark, manufacturer, or otherwise does not necessarily constitute or imply its endorsement, recommendation, or favoring by the United States Government or any agency thereof. The views and opinions of authors expressed herein do not necessarily state or reflect those of the United States Government or any agency thereof. 


\section{DISCLAMIER}

Portions of this document may be illegible in electronic image products. Images are produced from the best available original document. 


\begin{abstract}
SRI International conducted a set of impact tests with flat disks hitting water-filled chemical submunitions. One of these tests, called Gun-27, involved a 595 gram disk hitting the side of a submunition at $200 \mathrm{~m} / \mathrm{s}$. This test was simulated using the PAGOSA code with a materials model that was a good overall match to the data, and with a sequence of five mesh sizes. It was found that when a mesh was used which had at least five cells across the wall of the submunition, PAGOSA was able to provide reasonably satisfactory agreement with the test results, except for the partial fracture of a welded joint. One feature of the test that was reproduced very well by the simulation that used the finest mesh was the fracture of the diaphragm around its edge. Results are compared for all five simulations so that trends can be seen.
\end{abstract}




\section{BACKGROUND AND SUMMARY}

In the fall of 1996 three organizations simulated a model LEAP vehicle intercepting a theater ballistic missile, in which the warhead compartment was filled with water-filled chemical submunitions. The number of submunitions that were "killed" in the three simulations differed significantly. After a good deal of discussion over several months the question was asked, "What is needed to get the right answer?"

The full-up simulations by LANL and SNL were both done with Eulerian codes using cubic cells about $8 \mathrm{~mm}$ on a side. Although these sized cells are undesirably large the simulations filled the available computers to capacity. The CM-200 was used here at LANL, and the simulation took between 40 and 50 hours of cpu time.

This report answers the question by considering a SRI International test called Gun-27 in Ref. 1 . In this test a circular disk traveling $200 \mathrm{~m} / \mathrm{s}$ impacted the side of a water-filled chemical submunition. This test was simulated using the PAGOSA code on the CM-200 with a series of mesh sizes, and with a materials model that matched the test data for the steel in the test. It was found that the physical phenomena of the impact could be modelled well with a $1 \mathrm{~mm}$ mesh, and reasonably satisfactory agreement with the test results was obtained. The conclusion is that to do a reasonably satisfactory analysis of the full system intercept, a computer is needed that has $8 \times 8 \times 8=512$ times the memory of the CM-200, and which is $8 \times 512=$ 4096 times as fast. Such a computer would be able to simulate the full system intercept in about 24 hours of cpu time, because of improved programming recently added to PAGOSA that gained a factor of two in speed.

A video of the simulation of test Gun-27 was made and is available from the author. The video shows how the diaphragm ruptures, how the deformation wave travels around the walls, and how the walls straighten at late time.

\section{DESCRIPTION OF THE TEST}

The test called Gun-27 is described in Ref. 1 . Figure 1 shows a slice through the plane of symmetry of the PAGOSA simulations at the instant of contact. The submunition also has an axis of symmetry 


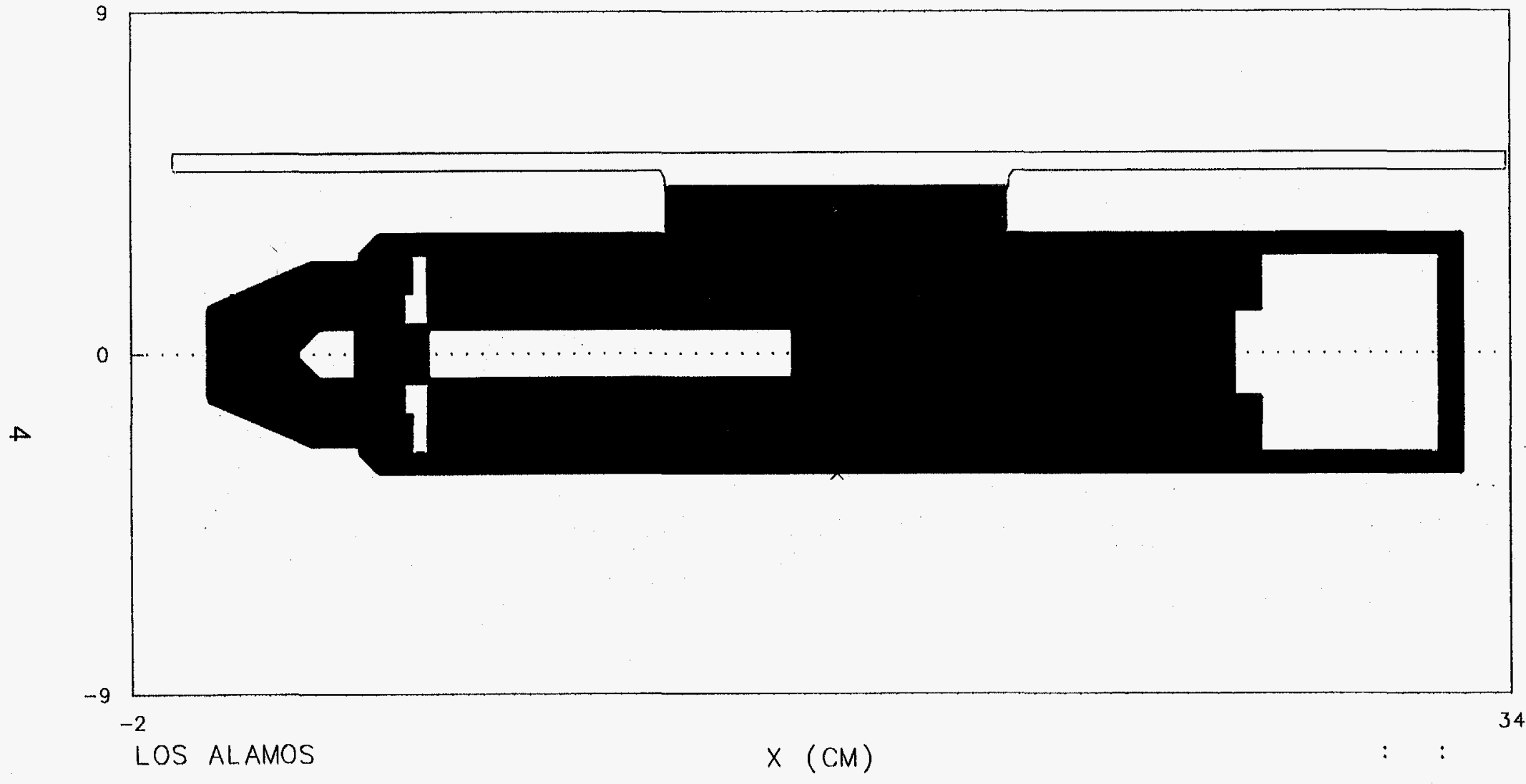

Figure 1. Configuration of the PAGOSA simulations at the instant of impact. This cut is through the plane of symmetry. The submunition also has an axis of symmetry along the dotted line. 
along the dotted line. The different parts of the submunition are colored blue, green, and red, and are all steel. The water inside the submunition is colored cyan. The air inside the submunition and the vacuum outside are colored yellow. The walls of the submunition (colored blue) are $5.74 \mathrm{~mm}$ thick. The hollow steel tube (colored green) inside the submunition is called the shock tube. In a real submunition it would contain a small pellet of explosive that would burst the diaphragm. The part containing the diaphragm is colored red, and the diaphragm is $0.508 \mathrm{~mm}$ thick and has a diameter of 22.2 $\mathrm{mm}$. The aft cap is colored green, and there is a step joint between it and the submunition wall. The region outside the diaphragm and inside the aft cap is a parachute compartment in a real submunition, but in the test as well as the simulation this region contained air. There was $5 \%$ ullage, so the water does not completely fill the inside of the submunition.

The impactor (colored red in Figure 1) is a cylindrical disk, 12.18 $\mathrm{mm}$ thick, with a diameter of $89 \mathrm{~mm}$. Its axis of symmetry is normal to the wall of the submunition. The mass of the impactor is about 597 $\mathrm{g}$, and its velocity is $200 \mathrm{~m} / \mathrm{s}$. The configuration of Figure 1 shows the disk at the instant of impact.

The results of the test are described in Ref. 1 as follows: "Upper canister fractured but top not removed, diaphragm ruptured." The fracture occurred at the welded joint between the wall and the fuze fitting (colored green). The fracture took place on the side of the canister opposite the impact side, but it did not fracture completely around the submunition. The weld is apparently a weak joint of the assembled submunition.

The flexture of the diaphragm is a standard problem in elasticity, and Larry Schwalbe has shown analytically that it should break around its outer edge; see Ref. 5 . This prediction was confirmed by James Colton at a meeting at SNL on March 11, 1997. Colton said the diaphragms are recovered intact quite regularly after the tests, and they look roughly like bent quarters, only thinner.

A photograph of the submunition after the test, on page 31 of Ref. 1 , showed a dent on the impact side, but on the opposite side the wall was very nearly straight. On page 77 of Ref. 1 the depth of the dent is quantified by the ratio $" \Delta R / R "=0.625$. This ratio will be discussed in Section 6 below. 


\section{CONSTITUTIVE RELATION FOR THE STEEL}

The stress-strain data for the steel was supplied by Colton in Ref. 2 , and are shown in Figure 2 as the circles. The functional fit is the solid curve and is in the Johnson-Cook form:

$$
\sigma=6.0+6.3 \varepsilon^{* *} 0.577 \text { (kbar) }
$$

As the reader can see this functional form is not entirely suitable to represent the entire data set. Nevertheless, given the constraint of the functional form the overall fit is quite good.

The equation of state used for the steel is the standard Gruneisen equation of state, with constants taken from Ref. 3:

$$
\begin{aligned}
& \mathrm{Us}_{\mathrm{s}}=0.457+1.49 \mathrm{Up} \mathrm{cm} / \mu \mathrm{s}, \\
& \gamma=0.50+1.43 \mathrm{~V} / \mathrm{V} 0, \\
& \mathrm{G}=0.775 \mathrm{Mbar} .
\end{aligned}
$$

\section{DISCUSSION OF PHYSICAL PHENOMENA}

Perhaps the most impressive feature of the simulations is the fracture of the diaphragm. The fracture is most vividly seen in the video, but even two static figures are impressive. Figures 3 and 4 show the simulation at an intermediate time and at a late time, respectively. In Figure 3 the diaphragm can be seen moving into the parachute cavity. It is emphasized that the fracture is a result of the numerical treatment; that is, there is no special feature of the constitutive relation that treats fracture. Even though the thickness of the diaphragm is only half an Eulerian cell width the use of material priorities in PAGOSA together with the code's interface treatment allows the diaphragm to be tracked throughout the simulation. In Figure 4 the result of a non-symmetrical pressure pulse has become apparent, with the diaphragm folding back to one side. It is apparent that the diaphragm will survive intact but bent, similar to that observed in the test.

The second phenomena of interest is a deformation wave that travels around the submunition length-wise. That is, on the side 


$$
F(X)=6.00+6.30 * X * * 0.577
$$

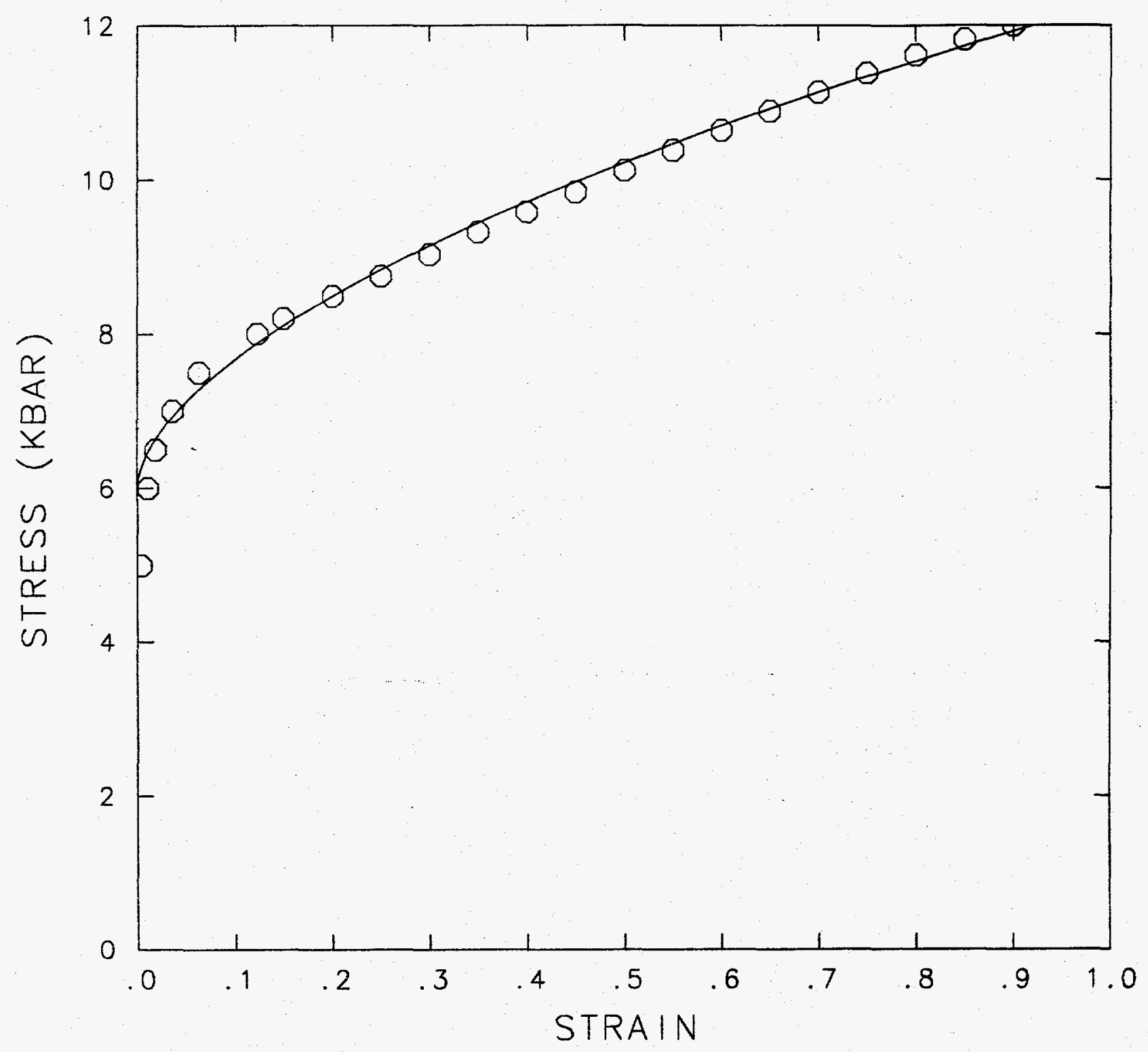

Figure 2. Comparison of stress-strain data (circles) with the functional form (solid curve) for the $\mathbf{4 1 3 0}$ steel used in the tests. 


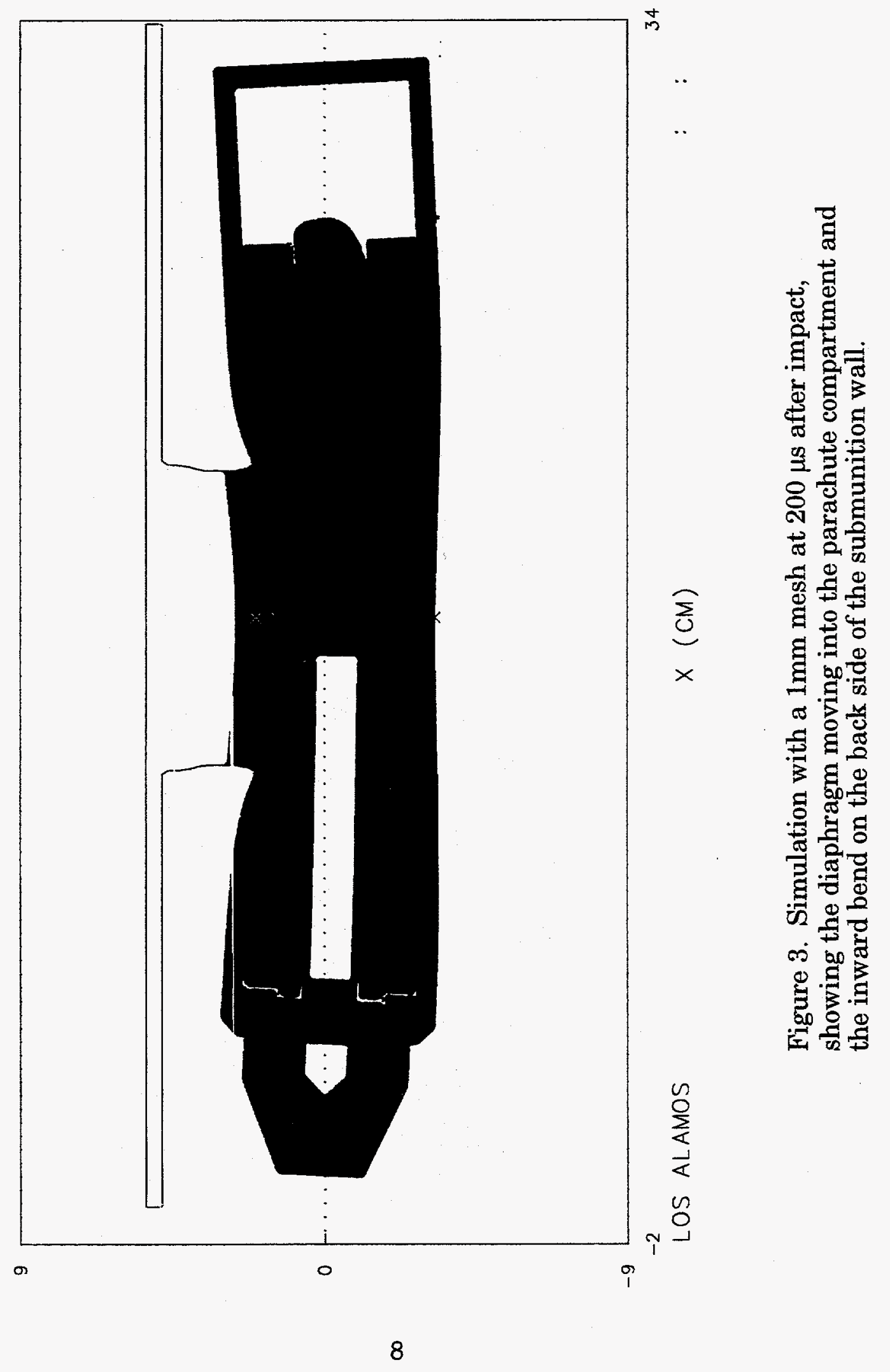




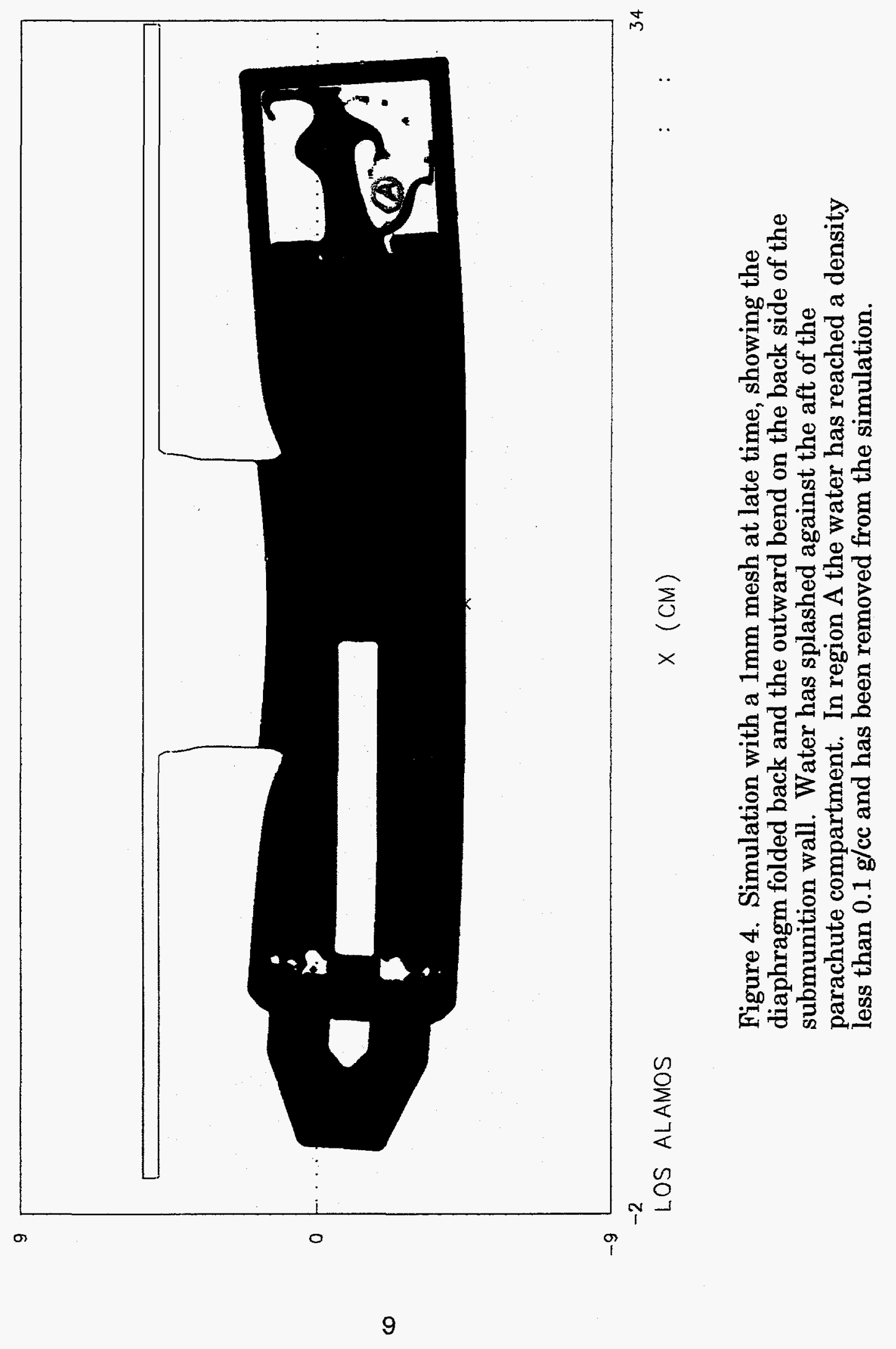


opposite the impact the ends of the submunition start to move before the center of the far side. The result is that the distance between the two sides reaches a minimum about $200 \mu$ s after impact, which is approximately the time of Figure 3 , and the back surface is bowed inward at that time. During the next $50 \mu$ s or so the far-side surface of the wall exhibits a phenomena reminiscent of the snap-through of a thin shell, going from bowed inward to bowed outward.

Thirdly, after about $500 \mu$ s the submunition begins to straighten. This phenomenon would not have been noticed except for viewing the video and looking along the edge of the submunition instead of from in front as is the usual position. Thus a second feature of the test is satisfied, namely the simulation is moving slowly toward having the back side nearly straight.

One feature of the test that is not reproduced in the simulation is the fracture at the joint between the wall and the fuze fitting (colored green), which is the part between the fuze and the wall. In the test this welded joint broke first on the side opposite the impact, and then the crack ran about half way around the submunition. That is, the fuze fitting was still attached on the impact side of the submunition. Speaking frankly, there does not appear to be any possibility that PAGOSA will be able to simulate such partial fracture in the near future.

The flow of water out of the opening where the diaphragm fractured can also be seen in Figure 5. At the starting time, the top figure in Figure 5, two Lagrangian tracer particles were placed in the water, $24 \mathrm{~cm}$ and $26 \mathrm{~cm}$ from the tip of the fuze. The one at $26 \mathrm{~cm}$, closest to the diaphragm, flows through the opening and into the parachute compartment, which is seen in the bottom figure in Figure 5 . (Some of the water in region $A$ in the bottom figure of Figure 5 reached a density less than $0.1 \mathrm{~g} / \mathrm{cc}$ and was removed from the simulation. This removal is necessary, because otherwise the water would get into a nonphysical portion of its equation of state and then cause the code to stop.)

The last physical phenomenon that will be discussed is the bending of the disk impactor. In Figure 4 the disk has a convex shape on the side toward the submunition, while in Figure 6 the disk has a concave shape on that side. The photograph in Ref. 1 shows that the disk in the test had the same general shape, although quantitative 

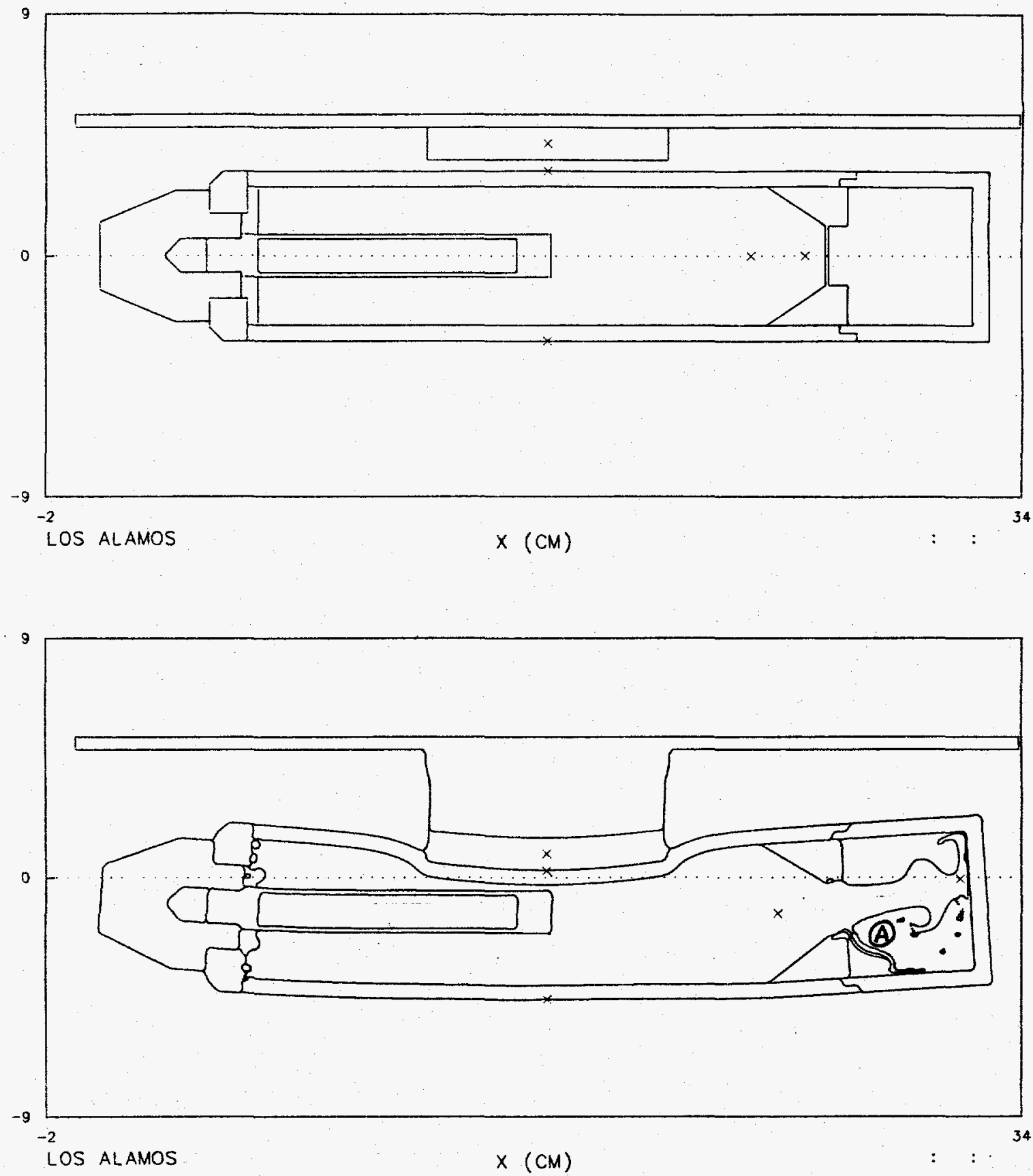

Figure 5. Two Lagrangian tracer particles were placed in the water at the start of the simulation. The one nearest the diaphragm flowed into the parachute compartment and splashed against the far wall. The other particle moved only a short distance toward the opening. 


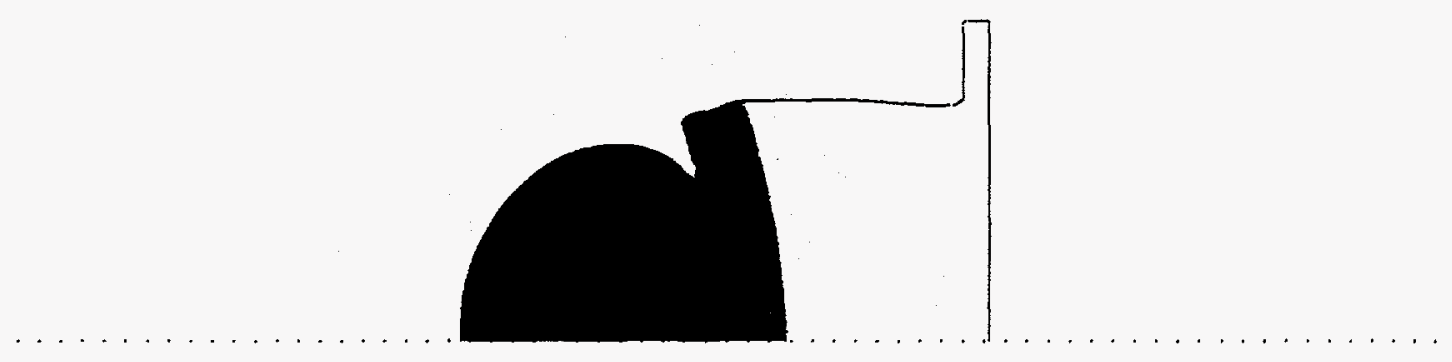

$X(C M)$

Figure 6. This cut from the $1 \mathrm{~mm}$ mesh simulation is at the same time as Figure 4, and is perpendicular to the axis of symmetry of the submunition near the end of the burster tube. Note the concave shape of the disk on the impact side. The scale of this figure is the same as Figure 4. 
comparison is not possible without the real disk. The reason this point is mentioned is that an early simulation, before the data in Ref. 2 was received, used a constant yield stress of $8 \mathrm{kbar}$ for the steel. With this elastic-perfectly plastic model the disk did not bend in the plane of Figure 7. The conclusion is that the real stress-strain behavior needs to be modeled, and an elastic-perfectly plastic model is not adequate.

\section{MESH-SIZE EFFECTS}

Five simulations were run of the test Gun-27, with five different mesh sizes: $8 \mathrm{~mm}, 6 \mathrm{~mm}, 4 \mathrm{~mm}, 2 \mathrm{~mm}$, and $1 \mathrm{~mm}$. Each simulation used cubic cells of the indicated size, and was run as a "half problem" with a plane of symmetry. The table below provides some data about the five simulations.

\begin{tabular}{crcr}
$\begin{array}{c}\text { Mesh } \\
\text { size (mm) }\end{array}$ & $\begin{array}{c}\text { Number } \\
\text { of cells }\end{array}$ & $\begin{array}{c}\text { Memory } \\
\text { Used (Gbytes) }\end{array}$ & $\begin{array}{c}\text { CPU time } \\
\text { (hours) }\end{array}$ \\
\hline 8 & 32,768 & 0.576 & 0.75 \\
6 & 32,768 & 0.576 & 0.80 \\
4 & 147,456 & 0.640 & 2.21 \\
2 & 360,448 & 0.832 & 8.65 \\
1 & $2,883,584$ & 4.19 & 113.3
\end{tabular}

A note needs to be made about the number of cells in the $8 \mathrm{~mm}$ and $6 \mathrm{~mm}$ simulations. PAGOSA has a limitation on the number of its cells, as described on page 5 of Ref. 4: the number of cells must be some integer multiple of $2^{* *} 13$. This restriction leads to a mesh larger than needed in some cases. A comment is also required about the CPU time for the $1 \mathrm{~mm}$ simulation: it was run in 23 segments over several calendar weeks, which meant having to restart from dumps some 22 times. Thus there was a small amount of overhead that was not present in the other four simulations.

In order to compare the results of the five simulations, Figures 7, 8, 9 , and 10 are compared to Figure 4 . When viewed as a sequence the following points can be made. First the fracture of the diaphragm is more pronounced with decreasing mesh size. Some kind of fluid flow is seen in Figure 8 for the $4 \mathrm{~mm}$ mesh, but the $6 \mathrm{~mm}$ and $8 \mathrm{~mm}$ mesh simulations did not have any water flow into the parachute compartment. 


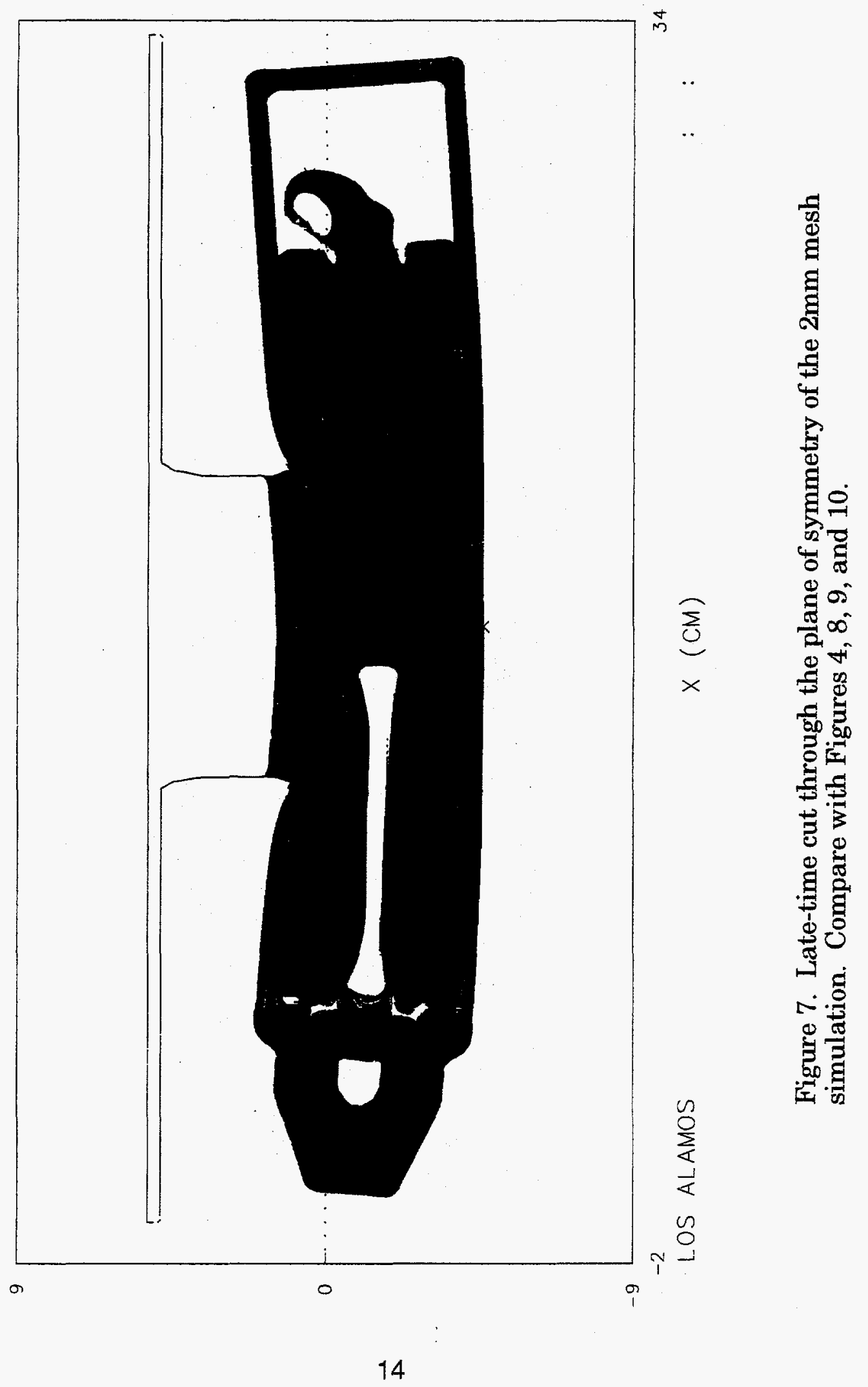




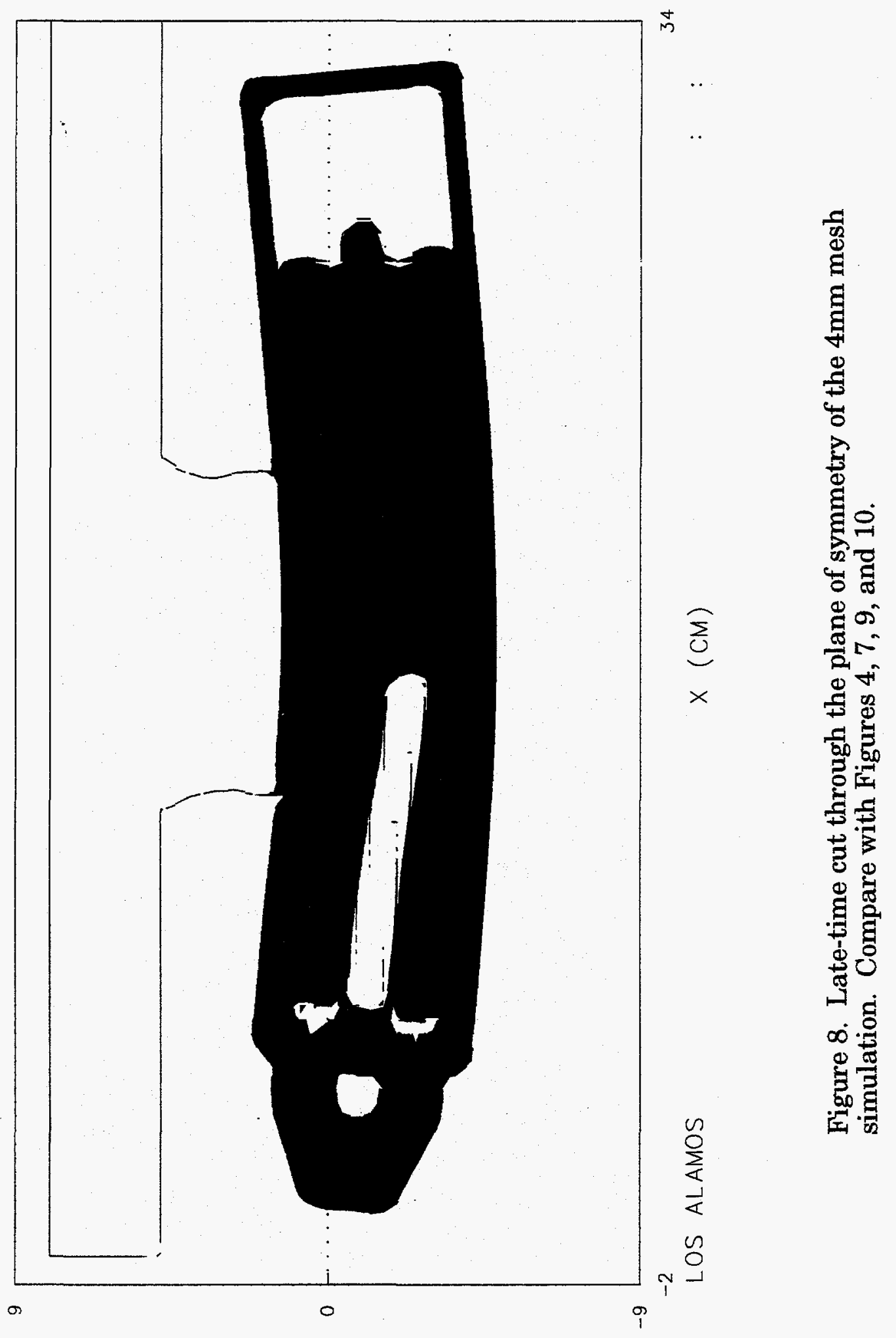




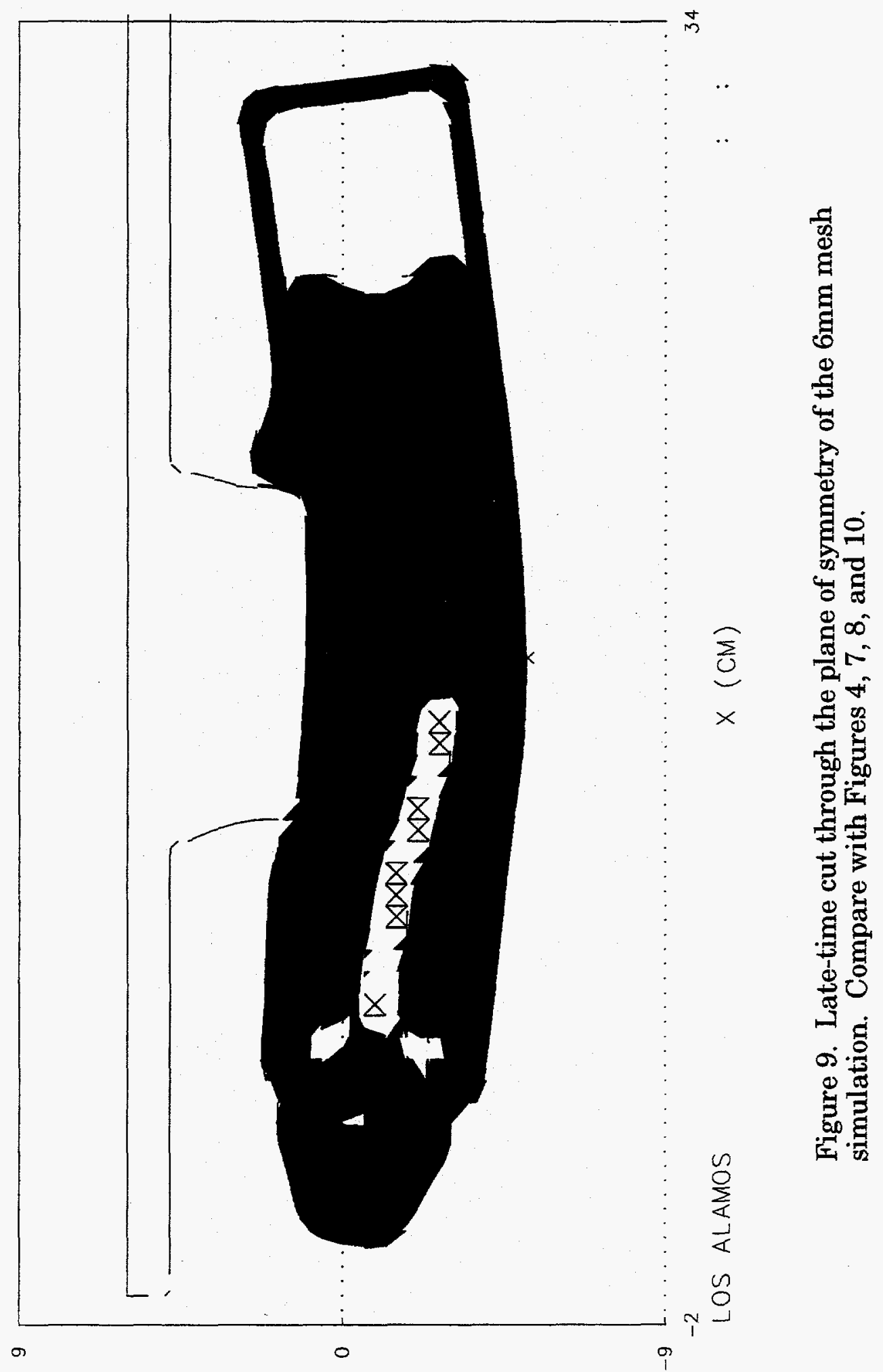




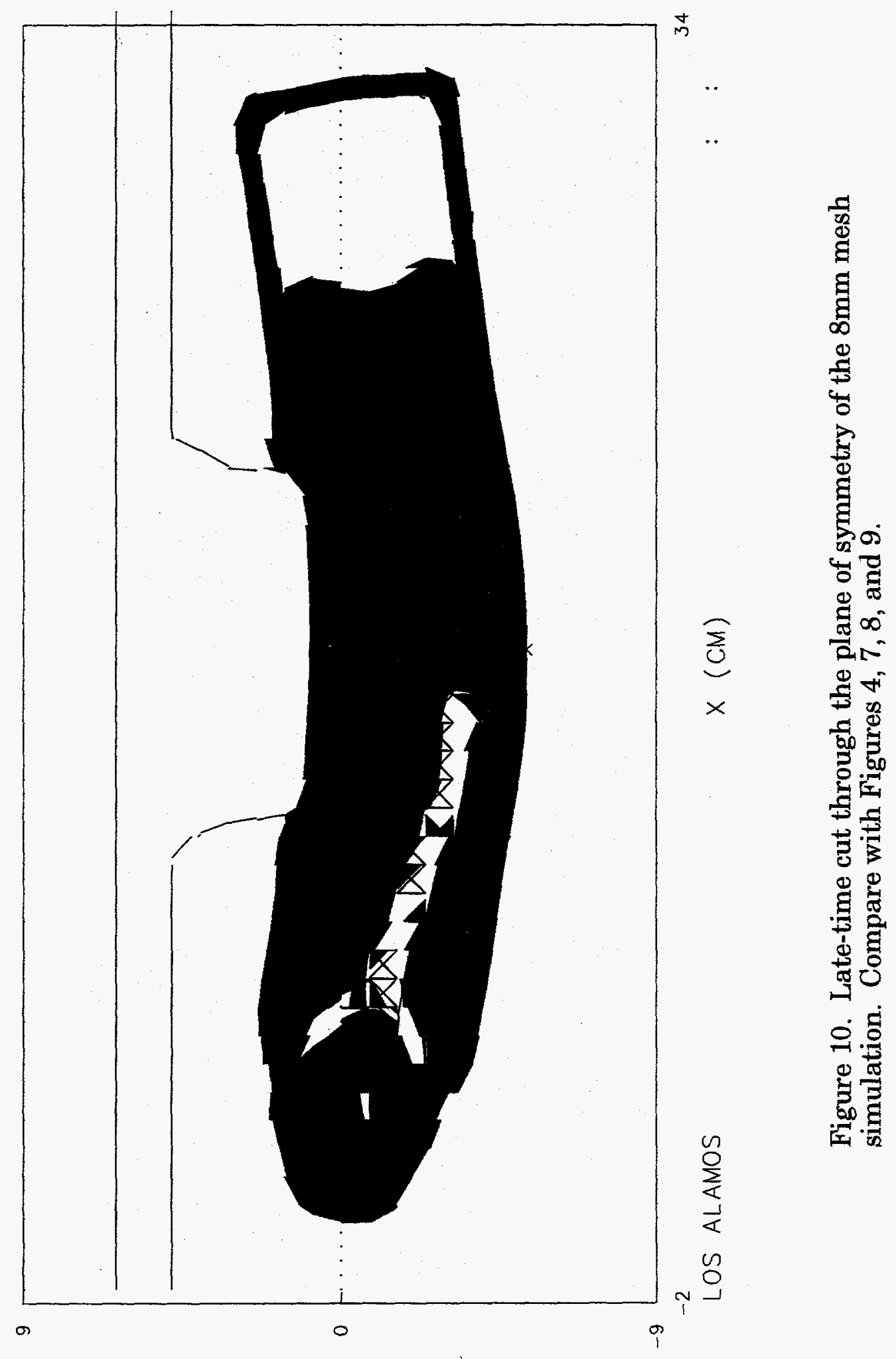


Second, deformation of the steel in the submunition next to the disk impactor increases with increasing mesh size to the point where, in Figures 9 and 10 with the two largest cell sizes, it is much greater that the test. In the $6 \mathrm{~mm}$ case there is even a non-physical bulge outward in the wall.

Third, the shock tube gets less well resolved as the mesh gets larger. The $8 \mathrm{~mm}$ mesh simulation has the steel tube incorrectly arranged with respect to the air inside it, as shown in Figure 10.

Fourth, the fuze (colored blue) and fuze fitting (colored green) are progressively less well resolved as the mesh gets larger.

Fifth, the shape of the wall on the side opposite the impactor has progressively increasing curvature with increasing mesh size.

Sixth, the step joint between the wall (colored blue) and the parachute compartment cover (colored green) is recognizable as a step joint in Figure 4 with the $1 \mathrm{~mm}$ mesh, but not in Figure 7 with the $2 \mathrm{~mm}$ mesh. While this is not significant with respect to the effects of interest, the reader can see how the step joint comes to be treated by the code when the mesh cannot resolve it.

Finally, it is important to view Figures $10,9,8,7$, and 4 as a progression leading toward some ultimately mesh-converged answer. When viewed together as a set they allow the reader to see trends and thus to reach conclusions that any one of them would not allow individually.

\section{DEFORMATION OF THE SUBMUNITION}

In the last paragraph of Section 2 it was mentioned that the depth of the dent was quantified by the ratio " $\Delta R / R "=0.625$. To see how well PAGOSA would model the depth of the dent, two Lagrangian tracer particles were placed on the opposite outer surfaces of the submunition wall under the center of the disk impactor, as indicated in Figure 5. After each simulation a post processor program was run to compute and plot the ratio

$$
\mathrm{D}(\mathrm{t}) / \mathrm{D} 0=1-\Delta \mathrm{D} / \mathrm{D} 0=1-\Delta \mathrm{R} /(2 \mathrm{R})
$$


versus time. The test result for this ratio at infinite time is 0.69 . The result for the 1mm mesh simulation is shown at the top of Figure 11, and the ratio is apparently approaching 0.76 . This is an error of about $10 \%$. The reason for the error is suggested in Figure 2, where there is appreciable error in the functional approximation when the strain is only $1 \%$. In this low-speed impact nearly all of the submunition experiences strains of this order, except immediately under the impactor. Thus the analytical stress-strain curve used in these simulations is too hard for the small strains of this particular application.

A comparison of the $D(t) / D 0$ ratio for the five simulations is shown in the bottom of Figure 11. The snap-through-like phenomenon is seen from 200 to $300 \mu$ s after impact, during which the ratio increases with time. After the local maximum at $300 \mu$ s there is a single reverberation, and then the submunition appears to settle down into nearly rigid motion. Notice that the two simulations with $8 \mathrm{~mm}$ and $6 \mathrm{~mm}$ meshes do not exhibit the phenomenon.

One aspect of Figure 11 is disappointing, namely the lack of an obvious convergence with mesh size, although up to about $220 \mu \mathrm{s}$ after impact there is very little difference between the $1 \mathrm{~mm}$ and $2 \mathrm{~mm}$ curves.

\section{PRESSURE HISTORY IN THE WATER}

The pressure in the water at the tracer point initially $24 \mathrm{~cm}$ from the tip of the fuze (the tracer on the left in the top figure of Figure 5) was plotted for each of the five simulations and the plots are presented as a collage in Figure 12. There is a great deal of smallscale structure that results from shocks reflecting off sides of the submunition and off its various parts. One obvious feature is that the peak pressure at about $80 \mu \mathrm{s}$ after impact doesn't change all that much. The width of the peak-pressure spike is a lot less, of course, with the $1 \mathrm{~mm}$ mesh than with the $8 \mathrm{~mm}$ or $6 \mathrm{~mm}$ meshes.

A physical phenomenon that should be seen at the tracer location is a reflected pressure pulse off the front of the submunition. This reflected pressure pulse is seen clearly in the $1 \mathrm{~mm}$ and $2 \mathrm{~mm}$ mesh simulations. There is also a hint of it in the $4 \mathrm{~mm}$ simulation at about $470 \mu \mathrm{s}$, but it is completely absent in the $6 \mathrm{~mm}$ simulation. 

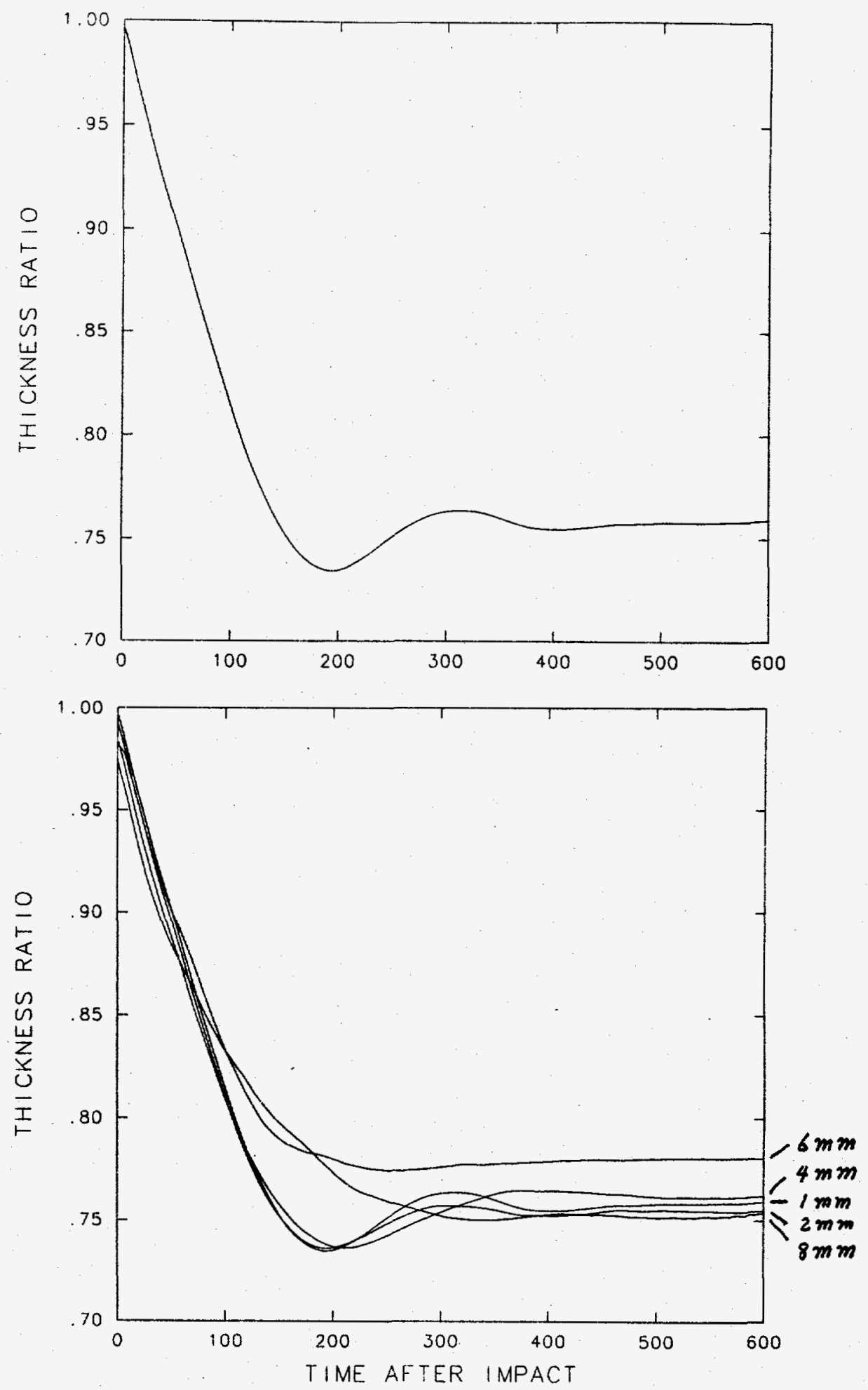

Figure 11. Plots of the diameter ratios. The upper plot is from the $1 \mathrm{~mm}$ mesh simulation, and the lower plot is an overlay of all five simulations. 

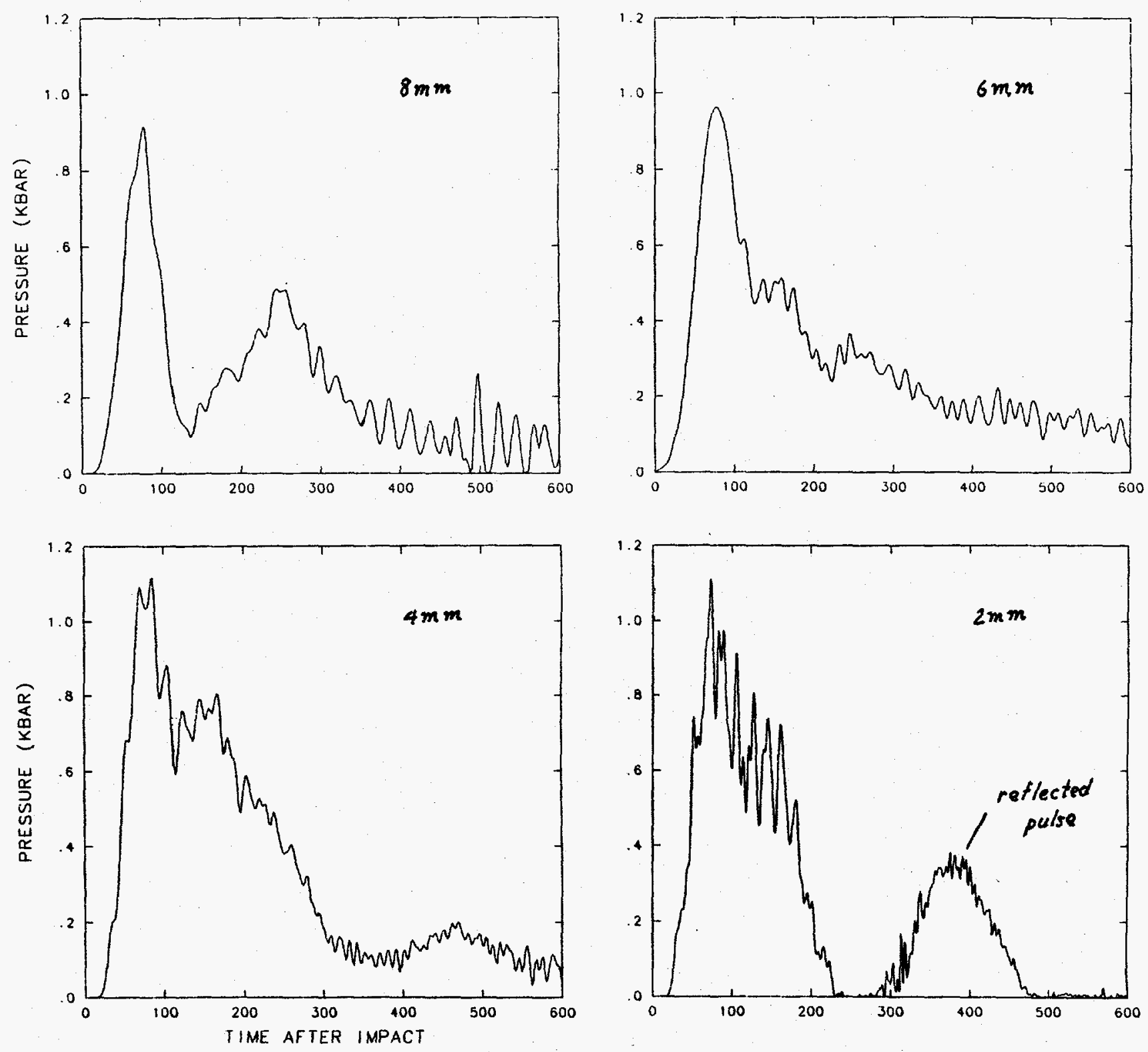

Figure 12. Pressure-time plots from the five simulations for the tracer particle that started $24 \mathrm{~cm}$ from the tip of the fuze.

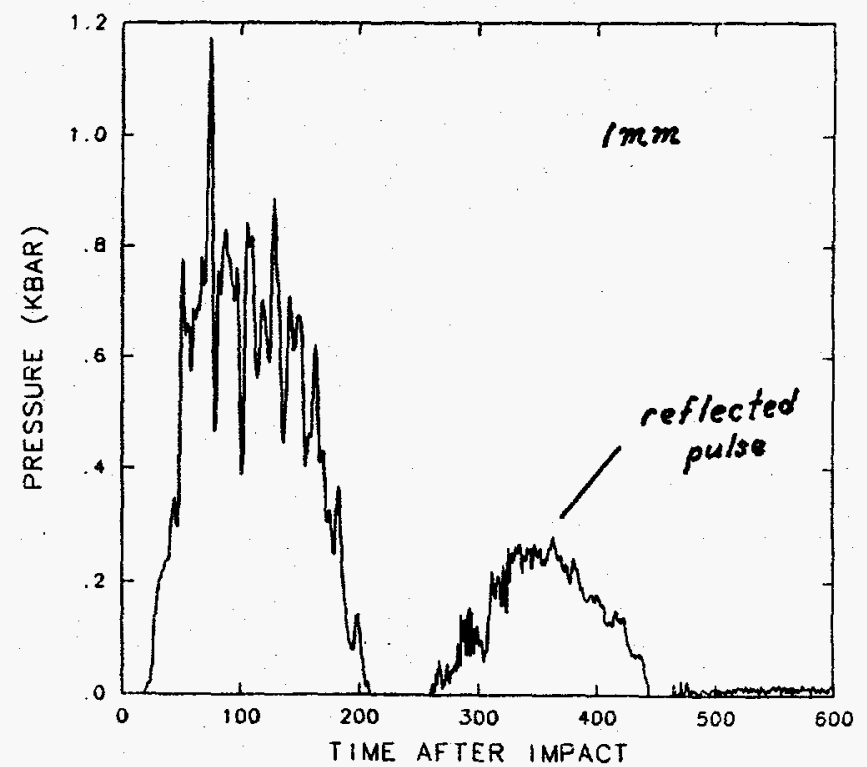


There is a curious pressure peak at $250 \mu \mathrm{s}$ in the $8 \mathrm{~mm}$ simulation. Some investigation suggests that it is the reflection off the diaphragm end. This spurious reflection might happen because the coarse mesh keeps the water completely contained.

\section{FINAL COMMENTS}

At this point it is appropriate to remind the reader that, although we have been speaking throughout this report of $1 \mathrm{~mm}$ mesh or $2 \mathrm{~mm}$ mesh, etc., it is really the mesh size relative to the material thicknesses that is important. Thus the wall of the submunition is $5.74 \mathrm{~mm}$ thick, so the $1 \mathrm{~mm}$ mesh gives 5 Eulerian cells across the wall thickness. This number of cells appears to give satisfactory representation of the physical phenomena during and after the impact. Also remember that the original missile intercept simulations were done with about an $8 \mathrm{~mm}$ mesh. Thus, if Figure 4 is something close to the right answer -- except for the fracture at the joint between the wall and the fuze fitting - then Figure 10 is what the full system simulation would produce. This comparison might seem discouraging, but remember it wasn't very many years ago that simulating a missile intercept wasn't possible at all.

The bottom line conclusion is that to get a reasonably correct analysis of the full system impact the mesh needs to be a factor of eight smaller in each of the three directions. This leads to a memory requirement that is $8 \times 8 \times 8=512$ times that of the CM-200. Since the Courant condition must be satisfied, there will be eight times as many time steps with this smaller mesh, and since each time step will require 512 times as many arithmetic operations, the speed requirement is $8 \times 512=4096$ times as fast as the CM-200 to do the analysis in the same amount of CPU time. This simple arithmetic indicates that the ASCI program is certainly going in the right direction, but it should adjust its goals a bit farther out.

\section{ACKNOWLEDGMENT}

The author wishes to acknowledge the assistance of Larry Schwalbe for several technical discussions throughout the course of this project. 


\section{REFERENCES}

1. James D. Colton, et al., "Load-Damage Relationships for Chemical Submunitions," DNA-TR-96-19(U), October 1996.

2. James D. Colton, "Stress-strain data for 4130 steel," 12 March 1997, private communication (unclassified).

3. Daniel J. Steinberg, "Equation of State and Strength Properties of Selected Matrials," UCRL-MA-106439(U), February 13, 1991.

4. Tom Bennion, "PAGOSA Input Reference Manual" (Rough Draft), September 30, 1996 (unclassified).

5. L. A. Schwalbe, "An Analytical Model for Submunition Diaphragms," LA-UR-97-1560(U). 